\title{
Crossrail project: building a virtual version of London's Elizabeth line
}

Malcolm Taylor CEng, MICE, MIStructE, MBA, MEng

Head of Technical Information, Crossrail, London, UK

The Crossrail project to deliver London's new Elizabeth line involves building two railways: a virtual one and a physical one. The virtual version was used to facilitate design, construction and subsequent operation of the actual railway, and they had to be achieved together. This paper describes the development of the digital engineering and building information modelling environment from the perspective and context of the virtual railway. It sets out the information principles adopted at the start of the detailed design stage of the project and describes the development of the common data environment in accordance with design collaboration standard BS 1192.

\section{Introduction}

The Crossrail project to deliver the east-west Elizabeth line railway across London, UK, comprises ten new stations, $42 \mathrm{~km}$ of tunnels, works to surface railways, and associated depots and maintenance facilities. With a $£ 14 \cdot 8$ billion funding envelope and in construction from 2008 to 2019, the new line will increase central London's rail passenger transport capacity by $10 \%$ and secure a $£ 42$ billion net benefit to the UK economy in present value terms over a 60 -year period.

Crossrail Limited was created as a subsidiary of Transport for London (TfL) to deliver the Crossrail programme to the requirements of sponsors TfL and the Department for Transport (Wright et al., 2017). Design and construction of the Elizabeth line is an example of a highly complex programme of projects to manage, as evidenced by the contractual arrangements required to deliver the systems and infrastructure.

With 23 framework design contracts and 83 construction and logistics contracts (often with multiple interfaces), the risk of miscommunication, duplication, use of out-of-date documentation and data interface problems was significant. The complexity was caused not just by the scale of the project but by the diversity and interdependence of activities and disciplines, both at station locations and along the route.

Most railway projects move into their operational phase with one maintainer. However, the Elizabeth line will be operated by Rail for London and have infrastructure maintained by Network Rail, Rail for London and London Underground Limited. This gives rise to additional complexity in having to meet separate and sometimes quite different information and data requirements.

From an information perspective, Crossrail Limited is building two railways - a physical version and a virtual version. Both need to be integrated, reliable, of high quality, trustworthy and consistent. The replication of the physical by digital information is critical as the virtual railway will be used to manage and maintain the physical for its projected life of at least 120 years.

\section{Digital information}

Information is a valuable resource and - from a project management perspective - is the currency used to make decisions of what to build when. The information and data environment is the medium used to interface and integrate the multiple projects within the programme (Figure 1). Within whole-lifecycle costs, maintaining and operating infrastructure can be two to five times the capital cost of construction. So, understanding how information is created and needed across the parts of the lifecycle is also fundamental to ensuring the future railway will be value for money in both the short and the long term.

In creating infrastructure, information in Crossrail Limited is only needed for two principal reasons: for legal or regulatory requirements (e.g. health and safety, environmental), and to make decisions either during implementation or operation. The latter requires the sponsor or client to understand the different information needs during design, construction, commissioning, operating and maintenance, so they can be procured appropriately.

The term 'building information modelling' (BIM) is relatively new (c. 2011) and is used to describe part of a digital information management environment. Its practice uses new technologies and processes to leverage utility from data and information across the lifecycles of creating and using infrastructure. The characteristics of BIM include the creation of a common data environment (CDE), with explicit digital information and data exchange requirements, together with planned, structured information requirements at each project lifecycle stage.

These new technologies and processes are heavily dependent on exploiting technology developments. In the 10 years since Crossrail's parliamentary phase in 2005-2008, the unit cost of processing power has decreased by 50 times, storage costs reduced by 15 times, bandwidth increased by 40 times and the cost of sensors halved. This is having a profound effect on the way Crossrail and other projects can manage and leverage trusted data in creating infrastructure, and then understanding how the infrastructure is behaving in use.

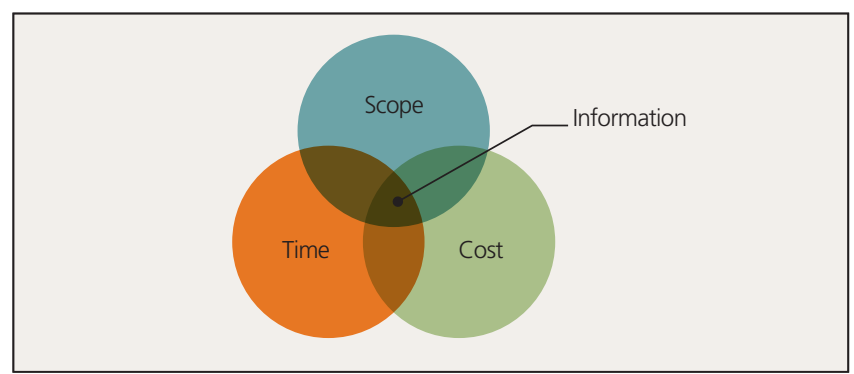

Figure 1. Information as the currency in project management 
In Crossrail Limited, BIM is seen as the process of creating and managing digital information throughout the whole life of the railway assets by using spatial modelling technologies (geographical information system (GIS) and three-dimensional (3D) computeraided design (CAD)) linked to databases of reliable information. Crossrail's technical information strategy has been informed by design collaboration standard BS 1192 (BSI, 2007), the principles of which focus on managing information flows to give emphasis on visibility and availability through the use of a CDE.

A CDE is simply a place in which information comes - or can be brought - together, and the process for storing, sharing and accessing data in an efficient and secure way. With very large amounts of digital data being created and shared during a project's lifecycle, the $\mathrm{CDE}$ is the ideal environment in which to promote a collaborative working culture across multiple groups, where everyone has access to the right information at the right time. Traditionally a CDE has three types of data within it: graphical models, non-graphical data and documents. What makes it a CDE is the shared use of this single information model across many organisations, engineering disciplines and contracts.

Modelling in BIM is often mis-considered and focused on 3D CAD. In Crossrail Limited the view is based on British standards and UK publicly available standards (PAS), where data models also have significant importance - especially when considering the maintenance and operations phases. A data model is simply any organised set of data in which individual elements are standardised and can relate to one another or to other things. They can be spreadsheets listing people, places, products or accounts through to more abstract inventories of attributes, entities and relations.

3D models represent a physical body by using a collection of points in space connected by geometric entities such as lines, triangles, curved surfaces and so on, and the surfaces can be further defined with texture mapping. 3D models are particularly useful during the initial stage of concept and design as they enable faster decision-making processes - stakeholders can get much more realistic impressions of what designers are seeking to achieve.

However, in maintenance, for example, data models forecasting when assets might fail are critical. 3D visualisations can be very effective for maintainers as they give an immediate spatial understanding to asset location (e.g. high up, in a confined space, close to track). So, modelling information is important across the full lifecycle of infrastructure (Figure 2).

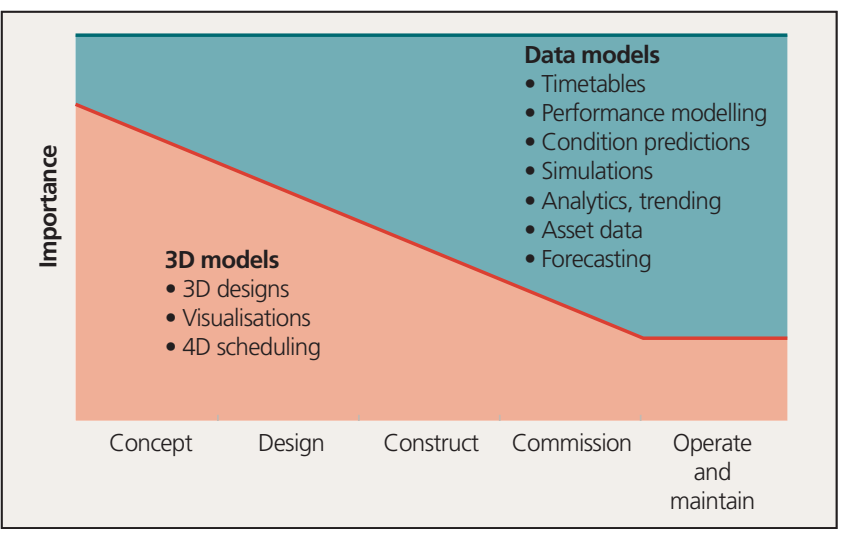

Figure 2. Importance of different model types at different lifecycle stages
The concept of 3D design and visualisations for Crossrail is not new. In 1995, designers for the railway were translating the architectural and engineering proposals into 3D images and using virtual reality software. Users could enter a virtual model of the Paddington station design current at that time, and explore the tunnels and architecture. But the BIM technologies available now enable these tools and techniques to be used by a much greater number of users. Underpinning the Crossrail BIM environment is the use of master data management to make sure that consistent and up-to-date versions of data are used across different areas of activity.

The scale of project information activity for Crossrail can be illustrated by the following
- over 5 million documents
- over 450000 drawings
- 660000 assets
- 8250 users of information database
- 450 CAD users.

The supporting information technology infrastructure to deliver a project of this size is also significant. Within the Crossrail system alone (not including contractor information technology), there are

- 250 servers

- 154 applications, ten cloud-based, also linked to 40 remote sites

- +1200 desktop personal computers

- +300 tablet users

- +600 mobile telephone users.

The totality of all information technology and management costs for hardware, software, licensing, staff and so on for the duration of the design and construction stages of the project is indicatively $£ 250$ million (about $3 \%$ of the total for the central section of the contract works delivered directly by Crossrail).

\section{Development of BIM and a CDE}

Good structured data availability began for the Crossrail project in the 1990s with a GIS. This has been a key information building block in all phases of the project. The requirements for a wide-ranging set of data sources meant that a GIS on its own was not sufficient for the programme and therefore surrounding the GIS a spatial data infrastructure was developed. This provided a framework of standards, policies and procedures that facilitated the creation and exchange and use of geospatial data and related information (maps, boreholes, utilities, etc.), which in turn helped the concept designs move towards detailed design.

The problem of engineering accuracy needed to be addressed. The UK's national coordinate system, the Ordnance Survey national grid, was used for the original Crossrail 1990s scheme. However, this was considered too coarse for the engineering accuracy required by Crossrail, as it could result in distortions of up to $200 \mathrm{~mm} / \mathrm{km}$ travelled due to the curvature of the Earth's surface. Therefore, a key workflow for a new projected coordinate system was developed to minimise the grid distortion within the Crossrail area. This became the London survey grid and combined existing Ordnance Survey stations with new ones, reducing overall distortion to $1 \mathrm{~mm} / \mathrm{km}$ travelled.

After parliamentary approval in 2008, when Crossrail Limited was established to move into designing and building the railway, 
the general information supporting the project was still held in a wide variety of stand-alone systems and software.

In 2008 Crossrail Limited took the first step in creating a CDE by creating a single CAD system that all designers would be required to use and collaborate in. This was based on the Bentley Systems ProjectWise and MicroStation software and uses a .dgn file format (the de facto format for infrastructure across TfL).

In 2009, Crossrail appointed 23 major framework design consultant contracts to begin the detailed design of the railway. The framework design consultants were required to undertake a full detailed design to Royal Institute of British Architects (RIBA) work stage $\mathrm{F}$ for civil and structural work, and to produce the preliminary RIBA work stage E design for mechanical, electrical, public health and architecture. Traditionally, each consultant would have undertaken their CAD designs separately and within their own business systems. For Crossrail, they were all required to use the client CAD system and related standards. Specific Crossrail Limited CAD standards were created and were mandated within the works information of all NEC 3 contracts.

The approach means Crossrail Limited is accountable for supplying and running a CAD service. By doing so, the single system approach ensures consistent CAD standards across all designs and a uniformity of solutions, and allows proper 3D design model coordination across different design disciplines. The framework design consultant designers were also co-located in Crossrail Limited offices, which meant that the system support for their CAD work was generally quick, and the information technology problems of remote working were limited.

With up to 450 users at any one time, it was also a very good value approach. Crossrail Limited continues to have an enterprise licence agreement with Bentley Systems to create savings through economies of scale, not paying a mark-up on consultant and designer rates (often 5-15\%) which would have happened had they used their own CAD systems.

The structure of the CAD processes and workflows were developed with the authors of the collaborative design standard BS 1192 part 1 . The software was heavily customised to reflect the standard and to bring in as much automated quality control as possible. The capability for 3D CAD drafting has been available for many years, but modern BIM technology and software capability meant that the traditional aspects of CAD drawing activity could be made more efficient and leveraged into robust spatial coordination and management of design interfaces between different disciplines.

\section{Information and asset breakdown structures}

It was important for Crossrail to define its broad asset requirements early on, initially creating a scope book in 2008 to capture the initial understanding of all the infrastructure and equipment at each facility required by the railway. This scope book was then refined through the various stages of the project.

The amount of data and information created by Crossrail Limited and contractors would be significant, and so it was also important to establish good data structure and primary information hierarchies based on

- location (location code plus work sub-locations)

- contract codes

- design disciplines
- organisation codes

- document types

- master deliverable list, standardised across multiple contracts

- asset functions

- asset classification (including attribute definition).

In 2009 the initial asset breakdown structure began development within configuration management software called AssetWise (previously called Enterprise Bridge). This is an object-orientated relational database, and enabled the delivery team to form relationships between different objects and events. As there was no single appropriate asset classification system, this was developed based on Uniclass together with a set of asset data definition dictionaries for each asset system and type, to give a common language for creating and sharing asset information. The following asset hierarchy was created.

1. Operating section (e.g. central section).

2. Facility (e.g. Tottenham Court Road station).

3. Primary functional unit (e.g. escalator).

4. Functional unit (e.g. steps).

5. Asset (e.g. step chain).

The term 'primary functional unit' is effectively a system, but the terminology is used to ensure no confusion with any information technology-related classification. Each asset has a unique tag identification, each coded by location, classification and function. It must also be remembered that collecting all the asset information is a progressive process. At the concept stage, only the numbers of primary functional units are known. At the completion of detailed design, each proposed asset can then be identified and given a specific tag identity, and the total number of assets can be determined.

Once the asset is installed and accepted, the individual asset attributes can then be collected, and only then can the information be prepared for handing over into maintenance. Crossrail Limited took an early decision to ensure the asset attribute data were collected separately and not contained within the 3D model itself. This helped keep the 3D models lighter and allowed a degree of interoperability between .dgn and .dwg file types.

An asset information management strategy was put in place in 2009 , to draw up a bespoke management plan, asset information standard, contract clauses, asset pointer, and asset information provision procedure. These were underpinned by the relevant standards, such as ISO 10007 for configuration management and ISO 55000 for asset management (replacing PAS 55), plus BS 1192.

Finally, it was also important to establish early on a consistent set of identification numbering systems for documents, drawings and 3D models. The following approach was used: $<$ Contract $>-$ $<$ Originator $>-<$ Discipline $>-<$ Document type $>-<$ Asset location/ Sub-location $>-<$ Incremental number $>$ (e.g. C330-SKC-O4-TPLCR076_PT001-00001).

For asset labelling identification, the following was used: $<$ LCS code $>-<$ Function $>-<$ Incremental number $>$ (e.g. CR501CRS-00002).

\section{Main CDE}

In BS 1192, a CDE is defined as 'a single source of information for any project or asset, used to collect, manage and disseminate all relevant approved files, documents and data for multidisciplinary 
Civil Engineering

Volume 170 Issue CE6
Crossrail project: building a virtual version

of London's Elizabeth line

Taylor teams in a managed process' (BSI, 2007). The main part of Crossrail's CDE developed during 2009-2011 primarily comprises a set of three linked databases: AssetWise for documents and data, ProjectWise for 3D CAD modelling and the Esri GIS.

Collectively the database holds about $10 \mathrm{~TB}$ or $90 \%$ of the key valuable business information (noting there is additional considerable temporary or work-in-progress information on Sharepoint sites and shared drives within the information technology system). Figure 3 shows the overall timeline when applications were brought into use, with the main elements and connectors between databases put into place during 2009-2011. Workflows and specific reporting continued to be developed for business processes up to 2016 as and when required.

There was no initial push to establish a CDE; it evolved and developed through the need to put into place the appropriate project information management systems. In 2010 Crossrail realised that its existing document management system would not be fit for purpose to manage the construction contracts. A new document control system had been brought into use in 2009 , but there was no rigour in its use. Many teams continued to work in silos and isolation, managing their data on shared storage drives to their own way of working.

A detailed review of options was undertaken, recognising there was no complete single system available to address all the Crossrail Limited information management issues and factors. The review included new document control software or using workflows within an existing database (AssetWise), which was already being used for configuration control and management of the evolving asset inventory breakdown structure.

After a detailed option assessment, AssetWise was selected as the way forward. As well as being cost-effective and already established software, critically it was realised this meant documentation could be directly related to assets and other data within the same repository, and workflows could be used to create business and project management processes as they were needed.

Getting people to use a new system had bigger organisational behaviour issues than technical ones. In a complex engineering project environment it is not possible to enforce a strict commandand-control approach to information management principles, particularly when teams have been working in their own ways for some time. A change programme called Project Beacon was set up, with support from external consultants, and extensive communication was required to develop the organisational and cultural shift to better information management.

In a phased approach over a seven month period, data was migrated from existing local hard drives into AssetWise and the initial workflows for document control rolled out through focused training and e-learning to the project teams.

From a project management perspective, the significant efficiency and cost benefits in using workflows within one database for specific processes instead of using separate multiple software solutions quickly became clear. Workflows were relatively easy to create and no additional software was needed, avoiding all the system integration and information technology issues commonly encountered when bringing new software into use with existing systems.

More importantly, the inputs, outputs and content of many transactional activities would be captured within this one database, either in the form of documentation or metadata. By having data properly structured in terms of work breakdown structure, contract breakdown structure, asset breakdown structure, and so on, information could easily be related as required (e.g. a pump asset to a specification and to a drawing and a particular facility), and reported on in a variety of ways needed by the business. Together with the ability to search the

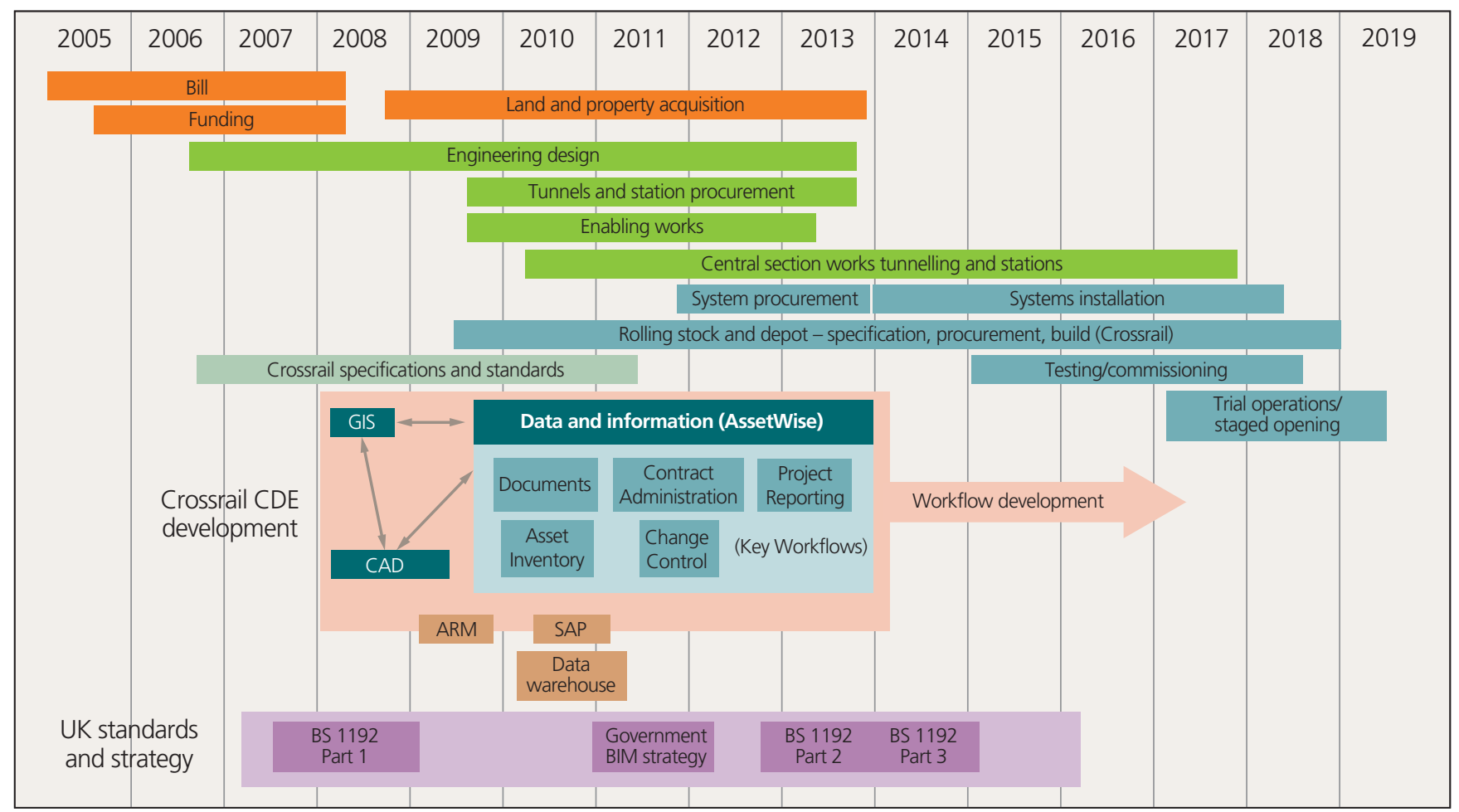

Figure 3. Indicative timeline of common data environment development against the overall programme 
database, this way of working made the process of finding information much more efficient and effective, with significant time reductions. The approach was entirely consistent with the BS 1192 approach to collaborative and integrated data management.

From the experience of creating workflows for document control, workflows were developed in AssetWise to manage contract administration following NEC3 contract processes, prior to letting the major construction contracts in 2011. The logic was quite simple: the transaction of sending a document from one party to another is similar to that of an instruction or a request, and it is quite straightforward to create template forms and event rules to manage the different types of activity required by the sender or receiver. The initial workflows developed were those that were seen as needed first, or gave the quickest immediate benefit.

Workflows were developed to focus on processes and activities related to the construction contracts being let from 2011 onwards (Figure 4).

The use of workflows as opposed to separate software solutions for different business processes saved at least $£ 8$ million per year in multiple software licence costs, and avoided the cost of additional information technology specialist resources to integrate the data. Only a small permanent team of four specialists was required to develop the workflows for the project. Even as the project moves towards contract completion and handover, development continues of workflows within the database for snagging, assurance compliance and other processes. Further details as to the data architecture strategy and approach are given in the Learning Legacy paper entitled Data Architecture Strategy (Goodall, 2017).

In 2010-2011, Bentley Systems established a connector between the ProjectWise CAD software and AssetWise, so that whenever a CAD drawing was published as a PDF, either as a draft or approved, it would automatically be stored in AssetWise. So, over 2 years,

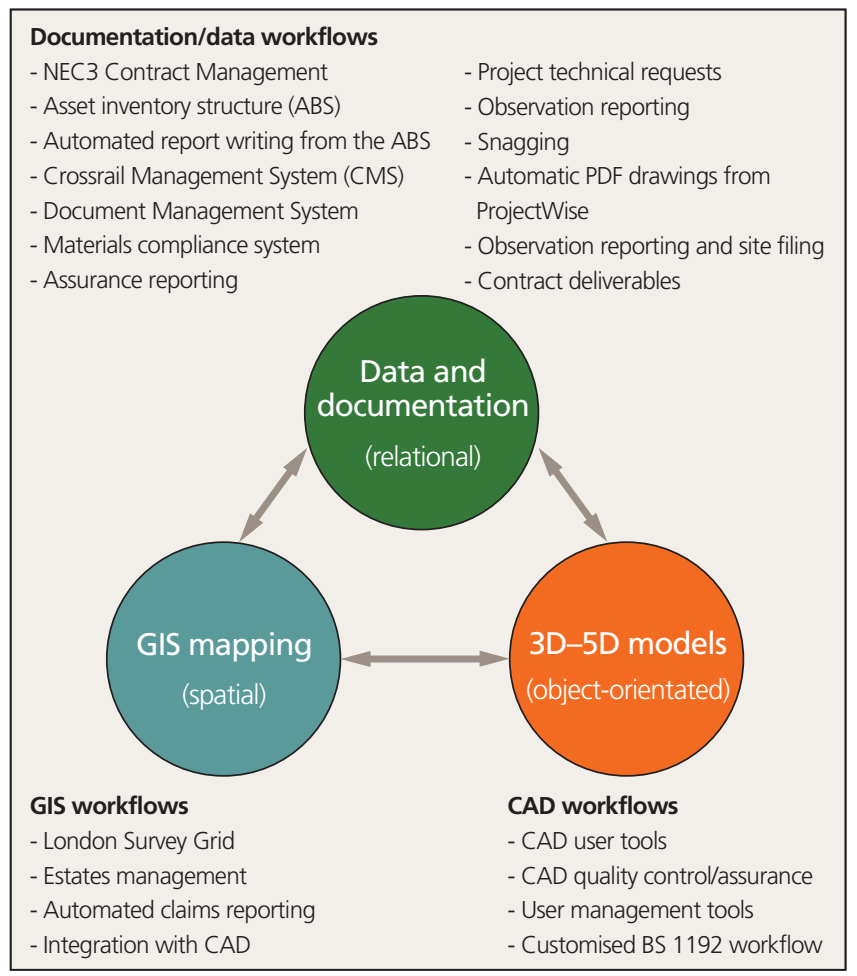

Figure 4. Data workflows within the CDE
AssetWise emerged as an information database and a single source for much of the technical information.

Between 2010 and 2013, the GIS continued to be developed. The key was to integrate the systems over a web-based intuitive interface and enable documents and data stored in the information database and models stored in Projectwise to be pulled out and consumed when using maps. Further information on the development of the project GIS can be found in the Learning Legacy paper entitled Building a Spatial Data Infrastructure for Crossrail (Irwin and Tamash, 2016). By 2013 the main Crossrail $\mathrm{CDE}$ had evolved and emerged as a group of linked databases.

Crossrail is not the only major project to have developed the CDE concepts of using workflows within databases to manage and control information. The $302 \mathrm{~km}$ Tours-Bordeaux high-speed rail in France also found significant benefits in taking this approach, in which two databases are used, one for documentation and the other for all geographical (spatial) data. Business management tools then create all the background reporting activity (Major Projects Association, 2017).

\section{Master data management}

As well as having a common environment to store and manage data, the processes and datasets needed to be properly structured and balanced. Master data management seeks to ensure multiple and potentially inconsistent versions of the same master data are not used in different parts of operations.

Behind each box in Figure 5 is the definitive list of items that have a common meaning across the project. The lines between boxes indicate that there is a relationship between items. For example, a contract will have its own characteristics, one of which is the party Crossrail Limited has entered into a contract with (namely the contractor). Similarly, a project will be made up of a set of contracts. The information that makes up these definitive lists is placed under change control. This means that each item has someone in the organisation responsible for ensuring that it is complete, correct and up to date.

Not all project documentation is held in AssetWise. From a programme control perspective, there was information in other business systems including Primavera (for scheduling), ARM (risk) and SAP (finance), which needed to be brought together to enable day-to-day management of contracts. In 2010-2012, a data management system (known as a data warehouse) was built to collect information from all of these systems for business reporting. Holding the overall model in one place meant that the relationships were under control. It also meant that the line of business systems only needed to hold the corporate data model entities that they used.

Transactions from the systems were loaded into the data warehouse once in every 4 week period. With this data model, the data warehouse can add up information to provide a consolidated view. It means that those people who use the line of business systems are not constrained by levels in a corporate hierarchy that add no value to their day-to-day task of managing information. Further details of this can be found in the Learning Legacy paper entitled Approach to Master Data Management at Crossrail (Palmgren, 2017).

\section{Contractor use of BIM}

The Crossrail construction contracts began to be progressively let from 2009, starting with advanced works or mobilisation contracts to 


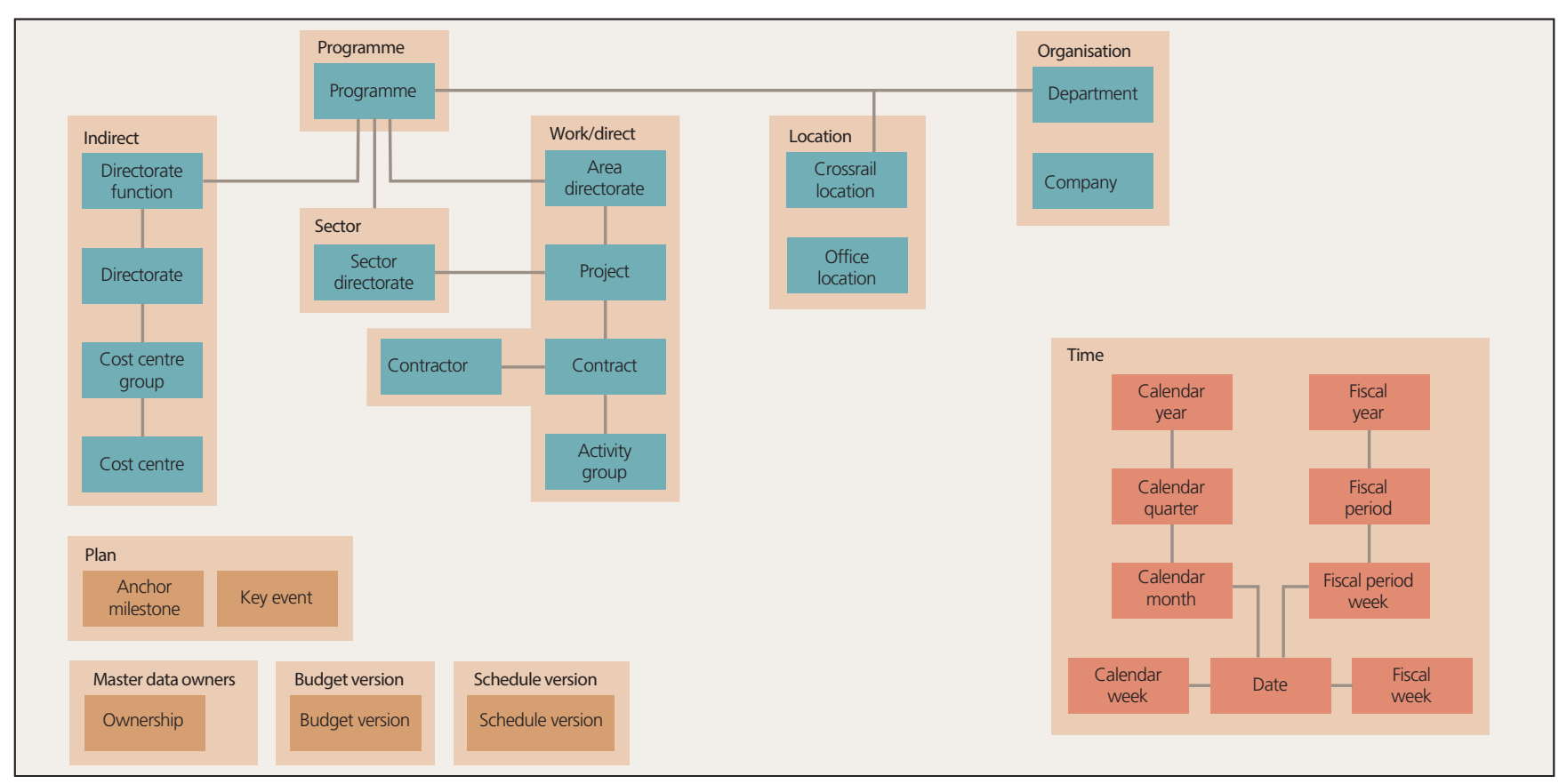

Figure 5. Master data management structure

prepare for the major station and tunnelling contracts. These contracts required the contractors to build the civil and structural designs that the framework design consultants had developed, and to take the RIBA stage E design for mechanical, electrical, public health and architecture, finish them (to RIBA stage F2) and build or install them.

Within the works information, the contractual clauses that spelt out the contract requirements were several simple but key information requirements. All contractors were required to use the project's electronic CAD management system - just like the framework design consultants - to undertake their CAD work. From 2010 to 2011, the works information stated that contractual correspondence could only be through using the contract administration workflows using the AssetWise electronic document and data management system. Emails and printed letters were not considered contractual. This ensured that all transactions were automatically captured and filed within the information database.

Unlike the design phases, in which provision of the information systems was relatively easy, being confined to the principal Crossrail Limited offices alone, the construction phase required over 40 remote working sites connected over the internet to the main systems. To assist with the understanding of the project information environment, an information academy was established with the main BIM software supplier and technology partner, Bentley Systems.

The 3D models were reasonably complex and a mixture of professional disciplines and contracts. The CAD environment in a BIM context enables not just each element to be designed but the spatial boundaries between each to be managed appropriately. The information academy aimed at enhancing internal and supply chain knowledge, driving improvements and encouraging best practice. All contractor and consultant personnel who attended the information overview sessions became entitled to use all relevant Crossrail Limited software (for ProjectWise, AssetWise, GIS, etc.) for free to avoid concerns about software licensing costs. Further details of this can be found in the Learning Legacy paper entitled Information Academy (Ahmad, 2016).
Contractors were generally comfortable with using the centralised CAD applications (ProjectWise SS2, MicroStation SS2, etc.), and many framework design consultants were employed directly as principal contractor designers for their mechanical, electrical, public health and architecture work. However, problems did arise when the contract designers sought to use the $3 \mathrm{D}$ models supplied to them by Crossrail Limited to continue with the RIBA stage E designs. Although the design drawings were complete as a PDF rendition, some associated 3D models had not been kept up to date. The principal cause of this was that the drawings are contractual deliverables and the models are not, and both Crossrail Limited and the consultants had been focused on getting the drawings ready for the contracts.

Occasionally neither had thought through the complete end-toend process to understand that as-built data may need to be handed over to another contractor and whose subsequent detailed design drawings would be reliant on the original models being correct. This led to rework and recreation of some 3D models by some contractors to enable their design to progress.

During construction, Crossrail Limited generally did keep most civil and structural models current. Most station contractors kept their mechanical, electrical, public health and architecture 3D models up to date, but some did not. The latter was partly because a few teams did not recognise the importance of having an up-to-date virtual model that represented the physical design of specific detail.

For example, cable trays are normally designed using software specifically focused on manufacture and the format is not compatible with Crossrail Limited design software. This can mean that the 3D model data for these details are not readily available for the system-wide contracts that take over the station towards the end of station mechanical, electrical, public health and architecture fit-out. This gives the system-wide contractors significant difficulty in understanding exactly what equipment should be where, without resurveying and rework - the cost of keeping the models up to date is insignificant compared to the cost to the system-wide contractors in familiarising themselves with the as-built details of the station. 
With respect to the information database, initially a number of contractors were not comfortable with having to use the client system for contract administration and request for information processes, and several suggested Crossrail Limited should adopt theirs as being already established. As with the use of the Crossrail CAD system, Crossrail Limited provided support through training and workshops.

Typically, each day during the 2012-2015 periods of design development and construction, there were some 450 people using the CAD system and 3000 using the AssetWise information database.

\section{Information and data quality metrics}

In the physical world, concrete and steel quality gets checked through processes in which samples are checked and then the material is accepted or rejected. Information requires the same degree of control and measurement to ensure the quality of information is of the consistent reliable standards necessary.

Crossrail Limited developed a series of quantitative metrics derived from the business systems using checked and recorded facts from databases and business systems. This created an accurate picture of technical information performance and data quality. While in abstract terms it seems obvious that data quality is critical to making sound informed decisions, often the pressure of activities on site means people using draft or unapproved data. Getting people to realise the risks associated with working this way took some time before behaviours started to change.

Crossrail Limited developed processes for reporting the following metrics on a 4 weekly basis for CAD in ProjectWise and 3D modelling performance, documentation quality in AssetWise, GIS usage, and asset inventory data collection and compliance. The metric information was widely published, and was not used as a critical indicator but as a focus to help improve performance. Figure 6 shows a typical example of published contract information.

Once data on information quality was published, behaviours changed. For example, evidence showed that in 2013, typically contracts were using only $25-30 \%$ of approved documentation on site. But after 6 months of publishing and using metrics to illustrate

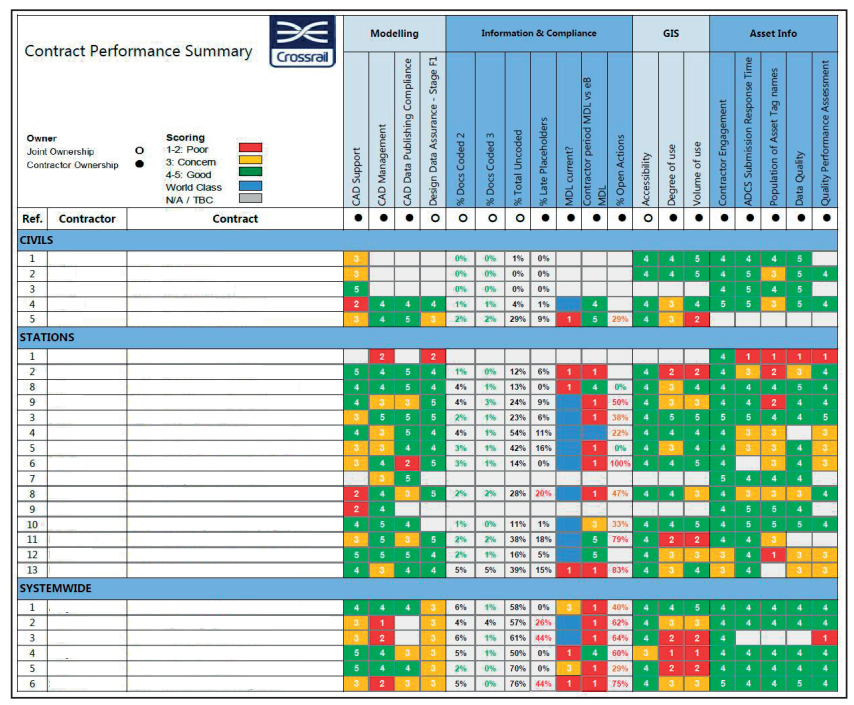

Figure 6. Typical reporting metrics for major contracts this, the figure had improved to $75-80 \%$. Further details are given in the Learning Legacy paper entitled BIM Metrics (Ahmad, 2017).

\section{Performance assurance framework and contract completion}

The Crossrail Limited tier 1 suppliers are evaluated twice annually - each over four reporting periods (one round), in accordance with the Crossrail Limited commercial and performance assurance procedure. The focus is on objectively measuring, assessing, supporting and assuring that tier 1 suppliers are operating to a level of performance that will enable Crossrail Limited's performance objectives to be met. The process includes geographically mapping contractors' performance against each other to drive competition, continuous improvement and world-class behaviours. Results and scores are then communicated across the programme by way of a chief executive officer forum and the Construction Industry Group See Learning Legacy paper Performance Assurance Framework (Wood, 2016).

The performance assurance framework is structured into nine sections as shown in Table 1. An assessment is conducted on the contract site and a quantitative metric review of outputs produced with findings, actions, key performance indicator metrics, trending and scoring. A final report (with combined scores plotted on a graph by project, function and contractor reference) is produced to provide an effective gauge for measuring performance improvement across contracts, against each other and from review period to review period. It became apparent that the contractors who came out with higher performance assurance framework scores were consistent in having better results with their information metrics and also in their ability to innovate - see the Learning Legacy paper entitled Innovation Programme Overview (Crossrail Ltd, 2015).

The metrics are used to provide oversight on quality and completeness of deliverables during the life of each contract. At the end of each contract, Crossrail Limited has an employer's completion process that demonstrates due diligence has been exercised prior to acceptance of data from the main tier 1 contractors. This requires information to be complete and compliant with the requirements of the programme, works information and relevant third-party requirements. The employer's completion process also supports the formal issue of contract defects and outstanding works lists.

Table 1. Performances assurance framework sections

\begin{tabular}{ll}
$\begin{array}{l}\text { Performance } \\
\text { assurance } \\
\text { framework } \\
\text { section }\end{array}$ & Description \\
\hline 1 & Continual improvement initiative \\
\hline 2 & Quality department and audit and surveillance \\
\hline 3 & Quality documentation \\
\hline 4 & Design coordination, submission, management \\
\hline 5 & Document quality and control \\
\hline 6 & Certification of works \\
\hline 7 & Crossrail Limited satisfaction of works \\
\hline 8 & Site tour \\
\hline 9 & Defects - identified and costs \\
\hline
\end{tabular}


Civil Engineering

Volume 170 Issue CE6
Crossrail project: building a virtual version

of London's Elizabeth line

Taylor
The employer's completion process comprises contract close-out checklists covering each of the business groups within Crossrail Limited. However, it is important to note that the commercial close-out of the contracts, including any settlements, final accounts, reconciliation of Crossrail Limited financial systems (SAP, Prism, etc.) is independent of the employer's completion process and is covered separately by Crossrail corporate. The technical information checklist form ' $\mathrm{C} 9$ - contract close-out checklist' extract in Figure 7 is typical. All checklists need to be signed off prior to enabling a contract to move forward as being completed commercially.

\section{Reflection on government construction strategy}

In May 2012, the UK government's construction strategy set out a series of objectives which defined BIM, including the need to deliver a structured sector capability to increase BIM take-up over a 5 year horizon as part of a joined-up plan to improve the performance of the government estate. The government task group defined the competencies and delivery required, and BIM levels $0-3$ were defined. A target was set to get public sector government projects to a BIM level 2 by 2016. As part of its activities, during 2012-2016 the BIM task group produced many excellent definitions of information requirements and documents and needed to deliver good BIM-enabled projects.

Fortunately for Crossrail Limited, these were all founded on BS 1192 part 1. Although Crossrail Limited did not have a specific employer information requirement document or BIM execution plan, information requirements were set out within the contractual works information volumes. The approach to CAD with BS 1192 software customisation, the use of integrated data management within AssetWise and the evolved CDE meant that Crossrail Limited fortunately met many of the main characteristics of the government's BIM level 2 targets of collaborative working, use of a shared 3D model and standardised file formats, and a centralised shared repository.

An independent assessment validated that Crossrail was effectively working at level 2. Some specific CAD aspects were initially only level 1 - for example, some simple design work was undertaken

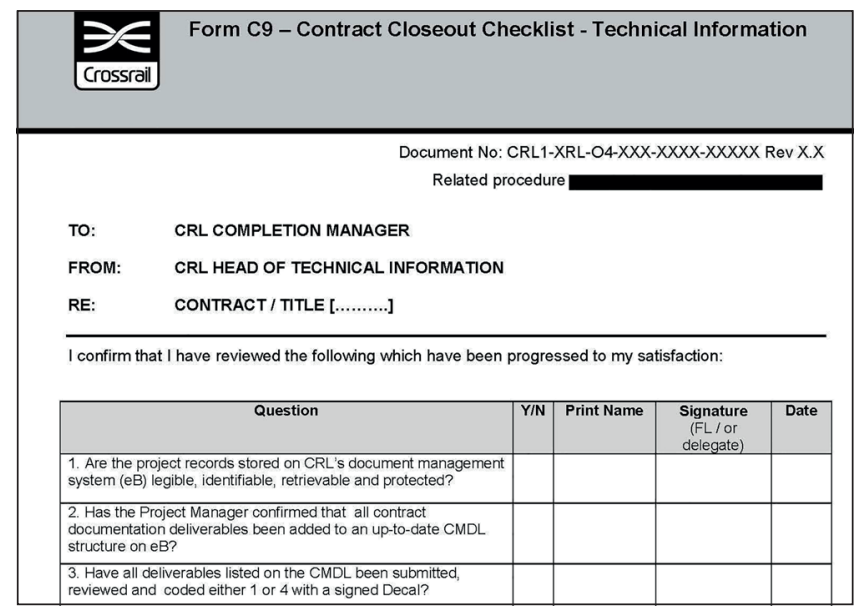

Figure 7. Extract from contract close-out checklist - to confirm the information received is complete prior to substantial completion of any contract in two dimensions for short-term expediency. Conversely, some of the integrated business information activities in which integrated workflows were used in AssetWise could be seen as beyond level 2.

\section{Summary}

The original pioneers of the BIM environment were land surveyors who established a comprehensive GIS in the 1990s.

Once Crossrail had been given parliamentary approval to proceed, the CDE developed over a number of years, primarily between 2009 and 2011. During this period, the GIS, CAD and documentation databases were developed and integrated sufficiently to create a set of systems, underpinned by sound master data management principles, to form a CDE that all contractors and personnel involved on the project were required to use.

The importance of developing a system for measuring the quality and compliance of information and data to standards is critical to all major projects.

A separate paper in the Crossrail Learning Legacy will describe the application of BIM, the handover of data into operation and maintenance and the tactical initiatives used to exploit the technologies available. The benefits of BIM and the lessons learned will be also set out.

\section{Acknowledgements}

The author would like to acknowledge the important role played by past and present members of the Crossrail technical information department and information technology directorate, and thank all of the team whose hard work, skills and commitment ensured the building information strategy was successfully delivered.

\section{References}

Ahmad T (2016) Information Academy. Crossrail Learning Legacy, London, UK. See http://learninglegacy.crossrail.co.uk/documents/informationacademy/ (accessed 09/06/2017)

Ahmad T (2017) BIM Metrics. Crossrail Learning Legacy, London, UK. See http://learninglegacy.crossrail.co.uk/documents/bim-metrics/ (accessed 09/06/2017).

BSI (2007) BS 1192:2007: Collaborative production of architectural, engineering and construction information. Code of practice. BSI, London, UK.

Crossrail Ltd (2015) Innovation Programme Overview. Crossrail Learning Legacy, London, UK. See http://learninglegacy.crossrail.co.uk/documents/ innovation-programme-overview/ (accessed 09/06/2017).

Goodall A (2017) Data Architecture Strategy. Crossrail Learning Legacy, London, UK. See http://learninglegacy.crossrail.co.uk/documents/dataarchitecture-strategy/ (accessed 09/06/2017).

Irwin D and Tamash N (2016) Building a Spatial Data Infrastructure for Crossrail. Crossrail Learning Legacy, London, UK. See http://learninglegacy.crossrail.co.uK/ documents/building-a-spatial-infrastructure-for-crossrail/ (accessed 09/06/2017)

Major Projects Association (2017) Report of seminar 193; Session 2 Developing a Digital Strategy.

Palmgren PO (2017) Approach to Master Data Management at Crossrail. Crossrail Learning Legacy, London, UK. See http://learninglegacy.crossrail.co.uk/documents/ approach-master-data-management-crossrail/ (accessed 09/06/2017).

Wood R (2016) Performance Assurance Framework. Crossrail Learning Legacy, London UK. See http://learninglegacy.crossrail.co.uk/documents/ performance-assurance-overview/ (accessed 09/06/2017).

Wright et al. (2017) Crossrail programme organisation and management for delivering London's Elizabeth line. Proceedings of the Institution of Civil Engineers - Civil Engineering 170(6): 23-33, http://dx.doi.org/10.1680//cien.17.00016. 